\title{
ZnO Nanoestructured Layers Processing with Morphology Control by Pulsed Electrodeposition
}

\author{
M. D. Reyes Tolosa ${ }^{a, *, z}$ J. Orozco-Messana, ${ }^{a}$ L. C. Damonte, ${ }^{\text {b }}$ and \\ M. A. Hernandez-Fenollosa ${ }^{a}$ \\ ${ }^{a}$ Polytecnhnic University of Valencia, Instituto de Tecnología de Materiales, Valencia 46022, Spain \\ ${ }^{b}$ Departamento Física, Universidad Nacional de la Plata, La Plata Buenos Aires 1900, Argentina
}

\begin{abstract}
The fabrication of nanostructured $\mathrm{ZnO}$ thin films is a critic process for a lot of applications of this semiconductor material. The final properties of this film depend fundamentally of the morphology of the sintered layer. In this paper a process is presented for the fabrication of $\mathrm{ZnO}$ nanostructured layers with morphology control by pulsed electrodeposition over ITO. Process optimization is achieved by pulsed electrodeposition and results are assessed after a careful characterization of both morphology and electrical properties. SEM is used for nucleation analysis on pulsed deposited samples. Optical properties like transmission spectra and Indirect Optical Band Gap are used to evaluate the quality of the obtained $\mathrm{ZnO}$ structures.

(C) 2011 The Electrochemical Society. [DOI: 10.1149/1.3593004] All rights reserved.
\end{abstract}

Manuscript submitted February 16, 2011; revised manuscript received April 28, 2011. Published May 23, 2011.

Solar cell devices with industrial application are stratified laminar materials, with several $\mathrm{dm}^{2}$ of exposed surface, processed by piling up several layers with different composition, each of them has a different function and complementary in the device. The performance of present commercial solar cells (that are based in semiconductors III-V, with Si poly or mono crystalline) is determined by the different fabrication process. ${ }^{1,2}$ In all of them, the production of diverse interfaces is the design factor, developed by growing different layers. The final properties of the semiconductor are defined by the type of boundary, the chemical species present, etc.... One of the determining factors in the final performance of the cell is its morphology, and the final product quality depends on the possibility of having a close control on the nucleation parameters. ${ }^{3,4}$ The optimization of these interfaces is a challenge for the photovoltaic industry, optimization must be based on a thorough understanding on the growth mechanisms. Likewise, the key for a successful implementation of photovoltaic energy is based on how industry attains a cheaper and more efficient process for cell fabrication. It is therefore necessary to reduce costs and production time of the cells without decreasing its performance. This requires more efficient production processes. These goals are common to all manufacturers of photovoltaic cells. Given the above scenario electrodeposition is selected as a favoured technique. This study develops the manufacture of inorganic layers of nanostructured $\mathrm{ZnO}$ for photovoltaic applications trough low-cost technology. In particular, Pulsed current electrodeposition (ED) is to be presented as a highly promising alternative. The aim of this study is to analyze the influence of waveform control for the electrodeposition current on the morphology as a tool to control the optical properties of the thin layer. The selected material $(\mathrm{ZnO})$ has a mesoporous nanocrystalline structure optimal for the development of hybrid solar cells. These materials have been characterized using different techniques to quantify the ability of the photovoltaic material, and at the same time, to correlate morphology and optoelectronic properties. In particular, the optical, electrical and structural best suited for the proposed application has been analyzed.

\section{Experimental}

Samples were prepared from ITO sputtered glass (resistivity at room temperature $10\left(\Omega / \mathrm{cm}^{2}\right)$. The substrates were cleaned using ultrasonic agitation in a mixture of distilled water with liquid neutral soap during $10 \mathrm{~min}$, rinsing in distilled water for $10 \mathrm{~min}$, and finally immersion in isopropanol for $10 \mathrm{~min}$ prior to drying in a nitrogen current. After cleaning, samples underwent $\mathrm{ZnO}$ electrodeposition by pulsed current.

\footnotetext{
* Electrochemical Society Student Member.

z E-mail: mareto@upvnet.upv.es
}

As a start point tests were based in previous galvanostatic electrodeposition research ${ }^{5}$ optimized for a current density of $1 \mathrm{~mA} / \mathrm{cm}^{2}$ for $10 \mathrm{~min}$. As for pulse conditions Xu's work ${ }^{6}$ was followed, the switching frequencies considered were selected between 0.2 and $1 \mathrm{~Hz}$, with switch off periods between 1 and 3 times the deposition time. The overall deposition time was calculated (after integration of the current applied over time) in order to get the same charge transfer in the pulse electrodeposition as in prior research over the topic by our team. ${ }^{5}$

Following previous references on the optimal parameters for electrodeposition, ${ }^{5}$ the films were deposited at $70^{\circ} \mathrm{C}$ from a solution containing the following electrolytes: $0,1 \mathrm{M} \mathrm{KCl} \mathrm{Rectapur}$ purity $>99 \%$ ), $\mathrm{ZnCl}_{2} 5 \times 10^{-3} \mathrm{M}$ (Panreac purity >98\%) and continuous oxygenation by a bubbling flow of $0,1 \mathrm{l} / \mathrm{min}$ of commercially pure oxygen. The electrodeposition was performed potentiostatically in a three electrode electrochemical cell with the substrate as the cathode, a Pt sheet as the counter electrode and a $\mathrm{Ag} / \mathrm{AgCl}$ electrode (SE) as the reference electrode $[\mathrm{VSE}=0,2$ (Ref. 13)]. In this paper all potentials are quoted versus SE unless otherwise stated. The potentiostat used for experiments was an Autolab PGSTAT302N with an ADC10M card for ultra fast measurement acquisition (1 sample every $10 \mathrm{~ns}$ ). The characterization was made with SEM, optical transmission spectra using a Hamamatsu model L2175 150w Xe source, and indirect band gap measurement.

\section{Results}

Cyclic voltammetry.-As a starting point, the cyclic voltammetry curve must be analyzed in order to identify the potential for the different reactions between the working electrode (ITO sputtered glass) and the solution. On Fig. 1 two reactions are identified, the first between 0 and $-1 \mathrm{~V}$, and the second between -1 and $-2 \mathrm{~V}$. Below $-2 \mathrm{~V}$ deposition of metallic $\mathrm{Zn}$ starts.

Electrodeposition curves and SEM micrographs.-The pulsed electrodepositon experiments were performed at constant current between -2 and $-5 \mathrm{~mA}$ based on galvanostatic previous work. ${ }^{7}$ For each current pulse the "pulse on" time lapsed from 1 to $2 \mathrm{~s}$, and "pulse off" time also from 1 to $2 \mathrm{~s}$. The number of pulses was calculated to achieve the same charge transfer as in the galvanostatic electrodeposition.

The voltage-current curves for $-4 \mathrm{~mA}$ samples are shown on Figs. 2 and 3.

The morphology of the $\mathrm{ZnO}$ nanocolumns is different for each electrodeposition technique, as shown in Figs. 4 and 5.

Optical characterization.-Optical characterization was performed for each sample. Transmission curves were obtained and are presented on Figs. 6 and 7. 


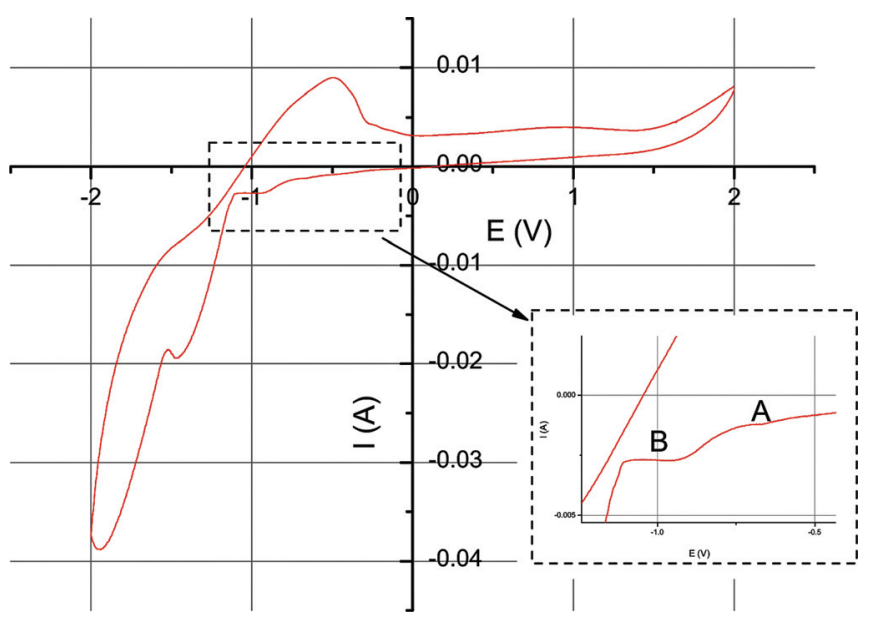

Figure 1. (Color online) Cyclic Voltammetry curve of $\mathrm{ZnCl}_{2} 5 \times 10^{-3} \mathrm{M}$ and $\mathrm{KCl} 0.1 \mathrm{M}$ solution, at $70^{\circ} \mathrm{C}$. The Zinc hydroxides (A) and Zinc oxide (B) formation reactions are showed in detail.

After an optical transmission characterization of results for different pulse combinations (" $\mathrm{ton}_{\text {on }}=1$ or $2 \mathrm{~s}$ vs. " $\mathrm{t}_{\text {off }}$ " $=1$ or $2 \mathrm{~s}$ ) it is clearly seen on Fig. 8 that the pulse combination rendering optimal an optimal transmission front was " $\mathrm{t}_{\mathrm{on}}$ " $=1 \mathrm{~s}$, independently of $\mathrm{t}_{\mathrm{off}}$ time.

Optical Band Gap.- It is important to determine accurately the optical band gap of the obtained semiconductor thin-film. Two techniques can be used for the optical characterization: spectroscopic ellipsometry measurements and the well-known envelope method from the transmission spectrum data. ${ }^{8}$

The absorption coefficient $\alpha$ of the electrodeposited film is obtained by using the data of the transmission spectrum. The relationship between the transmission $\mathrm{T}(\lambda)$ and absorption efficient $\alpha$ of a film follows

$$
T=W \exp (-\alpha \cdot d))
$$

and

$$
\alpha=\frac{B_{a}}{h v}\left(h v-E_{g}\right)^{\gamma}
$$

where $\mathrm{W}$ is nearly unity at the absorption edge, ${ }^{9} \mathrm{E}_{\mathrm{g}}^{\text {opt }}$ is optical band gap, $\mathrm{B}_{\mathrm{a}}, \mathrm{d}$ and $\gamma$ are constants. For indirect transition, $\gamma=2$ (Ref. 10). Then we have the equation

$$
\left(\frac{-h v \cdot \ln T}{d}\right)^{\frac{1}{2}} \propto\left(h v-E_{g}\right)
$$

By extrapolating the linear portion of $\alpha^{1 / 2}-\lambda$ curve, the optical band gap is obtained, as shown on Figs. 9 and 10.

\section{Results Analysis}

The first conclusion is that the current density of $1 \mathrm{~mA} / \mathrm{cm}^{2}$ is optimal for achieving wurtzite nanorods ${ }^{11-13}$ as it ensures a charge flow corresponding exactly to the theoretical kinetics of that reaction. Different rates correspond to a mixture of the wurtzite structure with some collateral products, ${ }^{13}$ or other crystalline structures ${ }^{14,15}$ that are not suitable for optoelectronic applications. ${ }^{16}$

It can be concluded also that the pulsed current electrodeposition allows a good control of the $\mathrm{ZnO}$ nucleation step, leading to a more pure wurtzite nanostructure. If the transmission spectrum is analyzed, the magnitude and position of the transmission jump provides a good assessment on the optical quality of the film determining in fact the optimum conditions for its application in hybrid solar cells. ${ }^{6,11}$

As shown in SEM micrographs columns appear scattered and with varying densities for galvanostatic electrodeposition conditions, specially when compared with pulsed current deposition results, where the nanorods layer is more compact and with better alignment. The dense morphology offers good optical properties. ${ }^{14,17-19}$

The reasons for this behavior lies on the nucleation step for $\mathrm{ZnO}$ nanostructures and its kinetics. As shown Pauporté and Lincot ${ }^{11}$ the electrochemical reactions that compete in the nucleation stage are

$$
\begin{gathered}
\mathrm{Zn}^{+2}+0,5 \mathrm{O}_{2} \rightarrow 2 \mathrm{e}^{-}+\mathrm{ZnO} \\
\mathrm{Zn}^{+2}+\mathrm{H}_{2} \mathrm{O}+0,5 \mathrm{O}_{2} \rightarrow 2 \mathrm{e}^{-}+\mathrm{Zn}(\mathrm{OH})_{2}
\end{gathered}
$$

Both reactions correspond to the two identified areas in the ciclovoltammetry curve presented in Fig. 1. Indeed, as Pauporté et al demonstrated $^{20}$ for our electrodeposition conditions $\left(p \mathrm{H}, \mathrm{Zn}^{+2}\right.$ concentration and dissolved $\mathrm{O}_{2}$ ) low potentials tend to develop an amorphous layer of $\mathrm{OH}^{-}$(Eq. 5) which then acts as a potential barrier leading to stabilizing the electrochemical reaction. ${ }^{4}$

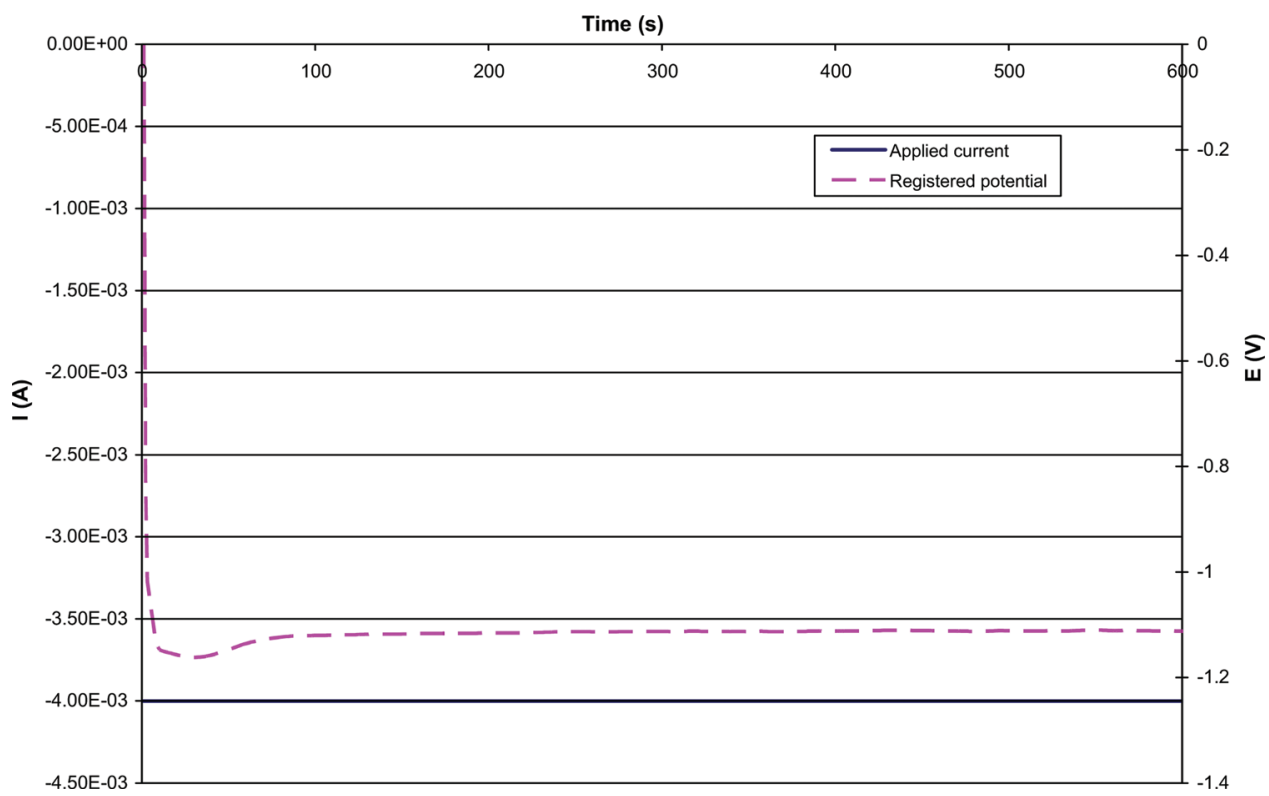

Figure 2. (Color online) (Current-Potential) vs. time curve for galvanostatic electrodeposition of $\mathrm{ZnCl}_{2} 5 \times 10^{-3} \mathrm{M}$ and $\mathrm{KCl} 0.1 \mathrm{M}$ solution, at $70^{\circ} \mathrm{C}$. 


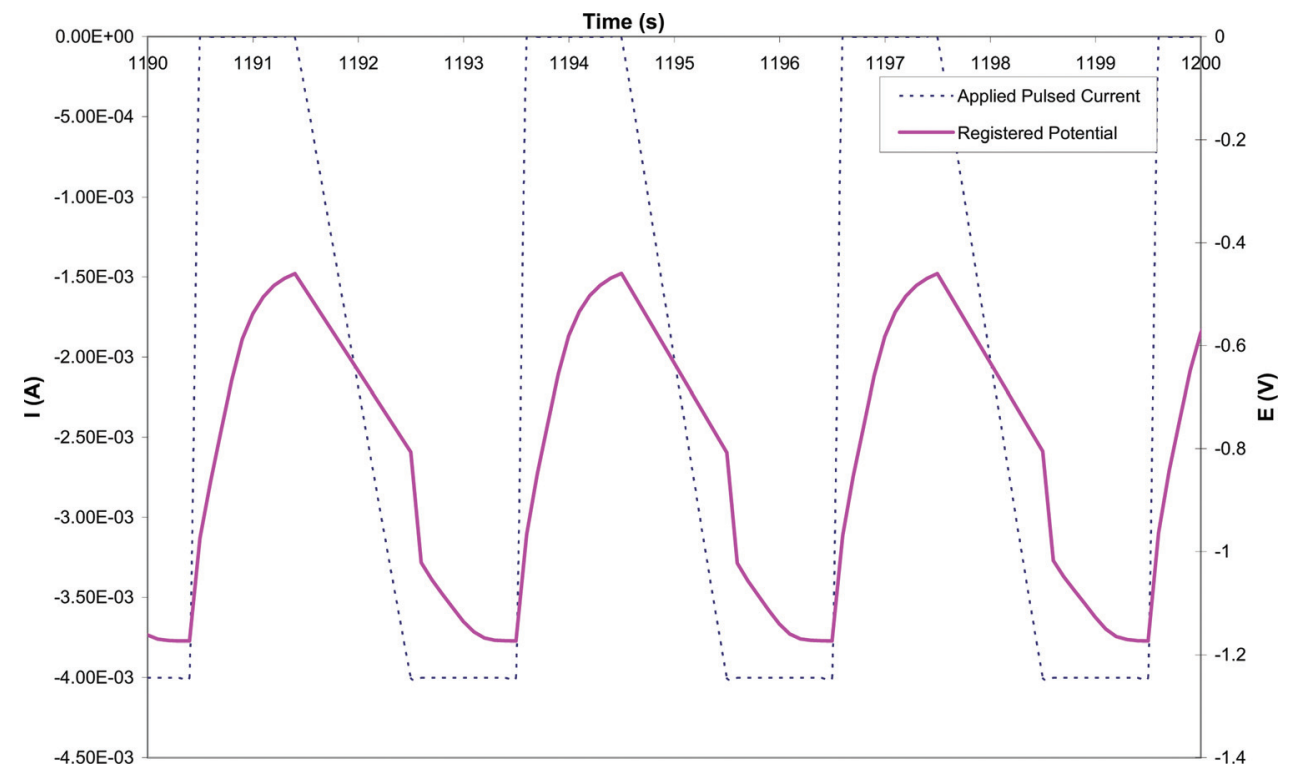

Figure 3. (Color online) (Pulse CurrentPotential) vs. time curve for pulsed electrodeposition of $\mathrm{ZnO}$ in a $\mathrm{ZnCl}_{2}$ $5 \times 10^{-3} \mathrm{M}$ and $\mathrm{KCl} 0.1 \mathrm{M}$ solution, at $70^{\circ} \mathrm{C}$.

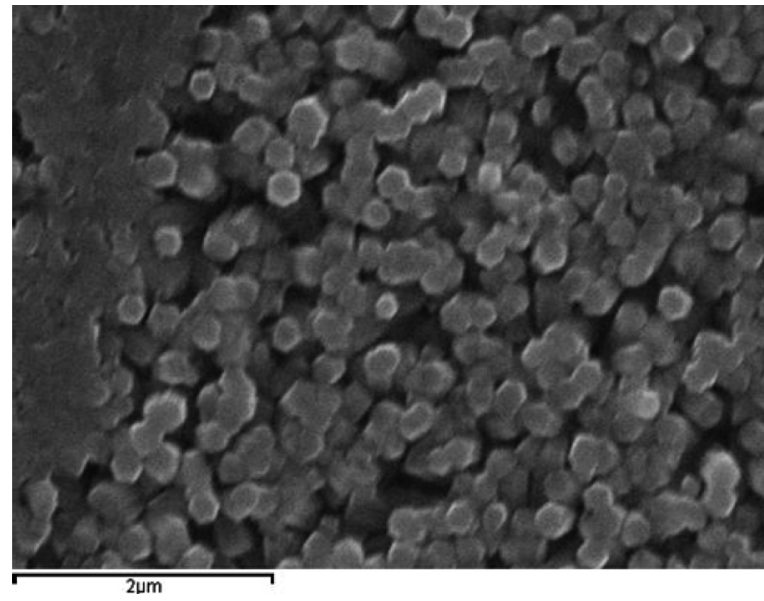

Figure 4. SEM micrograph of the $\mathrm{ZnO}$ nanocolumns for galvanic electrodeposition $(-4 \mathrm{~mA})$.

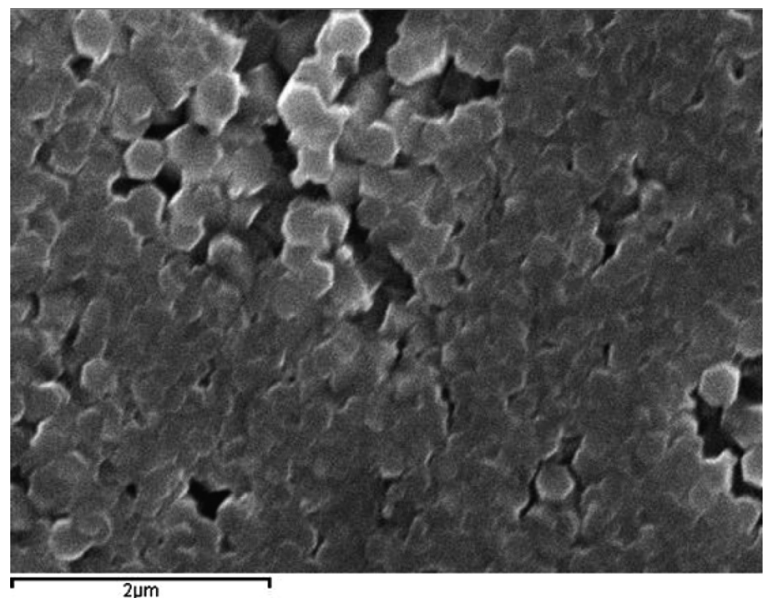

Figure 5. SEM micrograph of the $\mathrm{ZnO}$ nanocolumns for pulsed current electrodeposition $\left(-4 \mathrm{~mA}, \mathrm{t}_{\mathrm{on}}=1 \mathrm{~s}, \mathrm{t}_{\mathrm{off}}=1 \mathrm{~s}\right)$.

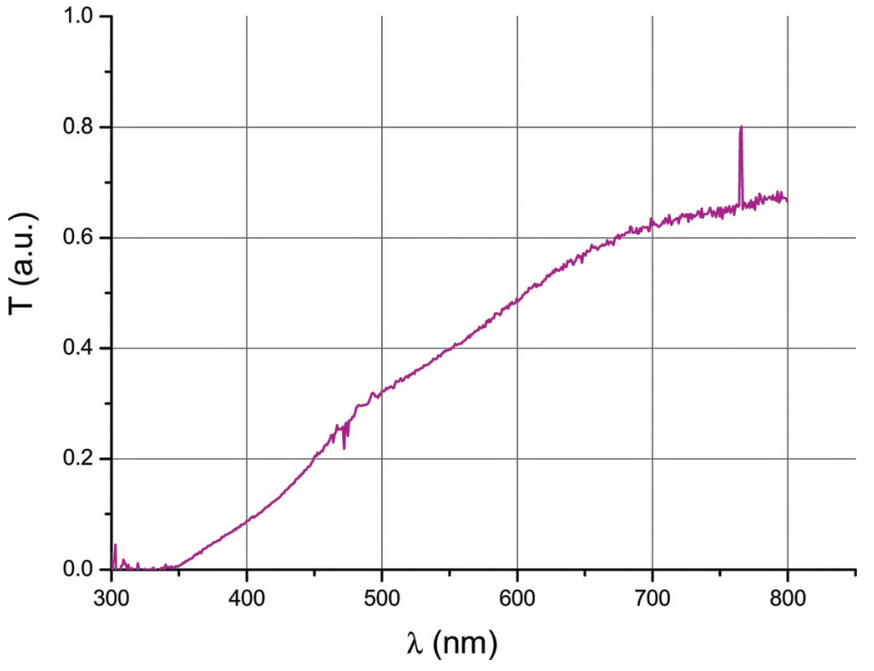

Figure 6. (Color online) Transmittivity for $\mathrm{ZnO}$ nanocolumns obtained by galvanostatic electrodeposition $(-4 \mathrm{~mA})$.

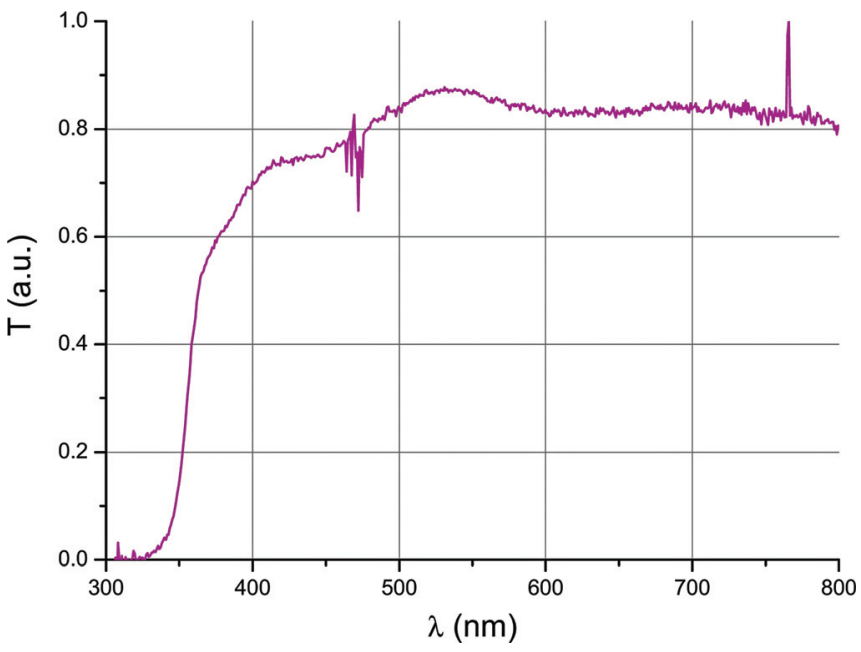

Figure 7. (Color online) Transmittivity for $\mathrm{ZnO}$ nanocolumns obtained by pulsed current electrodeposition $\left(-4 \mathrm{~mA}, \mathrm{t}_{\mathrm{on}}=1 \mathrm{~s}, \mathrm{t}_{\mathrm{off}}=1 \mathrm{~s}\right)$. 


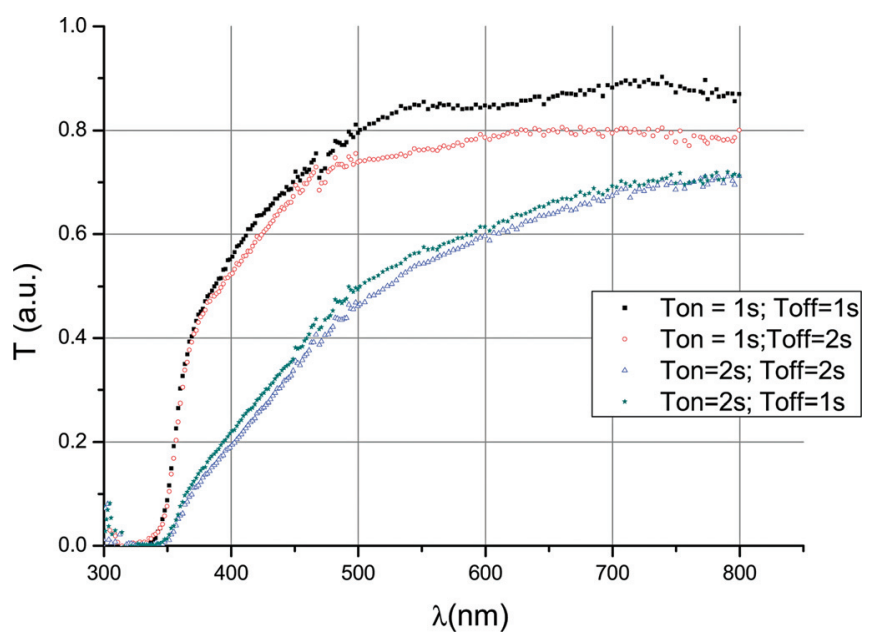

Figure 8. (Color online) Transmittivity for $\mathrm{ZnO}$ nanocolumns obtained by different pulsed current electrodeposition process.

In the first stage, all the surface is passivated creating an amorphous layer that later nucleates nanorods at a second stage. This nucleation is random and guided only by small variations on the surface topography (roughness) or concentration gradients, which yields a more dispersed nanocolumn growth and worse alignment.

However, in the case of pulsed current electrodeposition the alternating current field improves the reaction control through an elimination of concentration gradients, and so attaining a denser and better aligned growth of the nanorods. Further evidence supporting the previous hypothesis is the change in resistivity on the sample ongoing pulsed current electrodeposition, as show in Fig. 3, the slope variations are evidence of the changing conditions for the evolution of the reaction kinetics from Eqs. 5 to 4.

The optical properties are a consequence of this growth mechanism. As seen on Figs. 9 and 10a better fitting of the curves to the

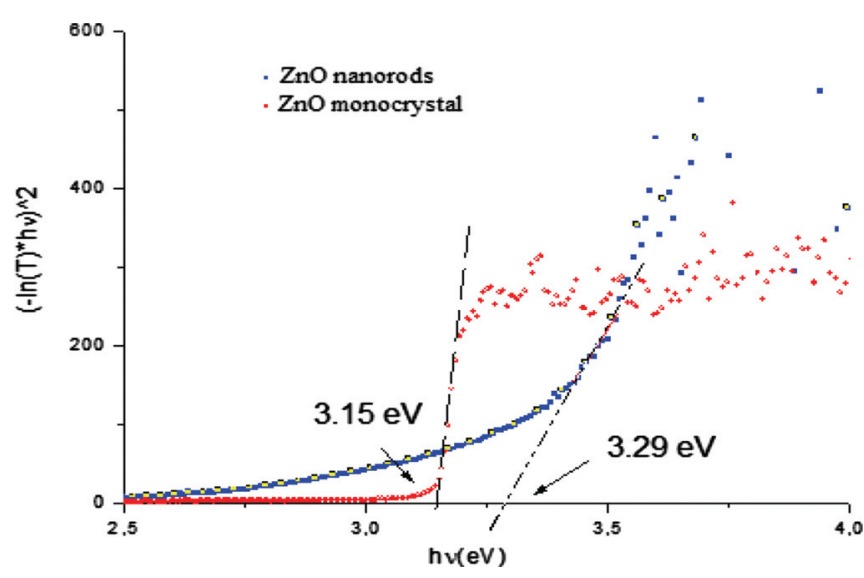

Figure 9. (Color online) Optical Band gap for $\mathrm{ZnO}$ nanorods obtained by galvanostatic electrodeposition.

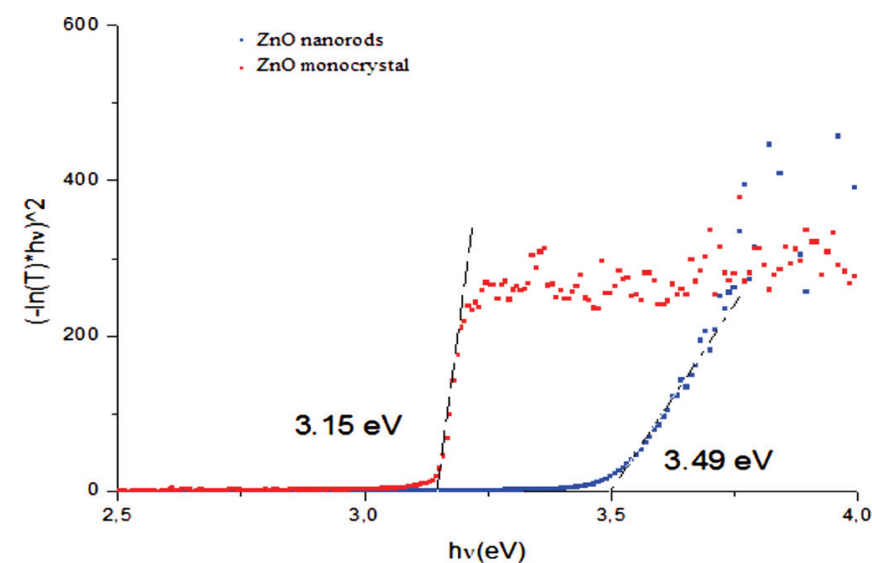

Figure 10. (Color online) Optical Band gap for $\mathrm{ZnO}$ nanorods obtained by pulsed current electrodeposition.

actual theoretical model indicates that the layer is following closely the theoretical basis.

\section{Conclusions}

The experimental procedure for pulsed current electrodeposition presented on this paper allows the fabrication of high quality $\mathrm{ZnO}$ thin films by a simple and effective procedure.

\section{References}

1. P. Fath, H. Nussbaumee, and R. Burkhardt, Sol. Energy Mater. Sol. Cells, 74, 127 (2002).

2. W. Neu, A. Kress, W. Jooss, P. Fath, and E. Bucher, Sol. Energy Mater. Sol. Cells, 74, 139 (2002).

3. T. M. Bruton, Sol Energy Mater. Sol. Cells, 72, 3 (2002).

4. P. Geigerr, G. Hahn, P. Fath, and E. Bucher, Sol Energy Mater. Sol. Cells, 72, 155, (2002).

5. V. Donderis, J. Orozco, J. Curiel, J. Cembrero, M. A. Hernández-Fenollosa, J. Nanosci. Nanotechnol. 10, 1 (2010).

6. L. Xu, Y. Guo, Q. Liao, J. Zhang, and D. Xu; J. Phys. Chem. B, 109, 13519 (2205).

7. V. Donderis, J. Orozco, J. Cembrero, J. Curiel, L. C. Damonte, and M. A. Hernández-Fenollosa; J. Nanosci. Nanotechnol., 10, 1-6, (2010).

8. Z. Zhanxia, Z. Yan, Y. Huacong, and M. Zhongquan, INEC Nanoelectronics Conference 2008. IEEE International

9. Y. Du, M. S. Zhang, J. Wu, L. Kang, S. Yang P. Wu, And Z Yin, Appl. Phys A,76 1105 (2003).

10. A. Nakajima, Y Sugita, K. Kawamura, H. Tomita, and N. Yokoyama. Jpn. J. Appl. Phys. Part 2, 35, L189 (1996).

11. T. Pauporte, and D. Lincot, Electrochim. Acta, 45, 3345 (2000).

12. M. Izaki, S. Watase, and H. Takahashi, Adv. Mater., 15, 2000 (2003).

13. R. Könenkamp, R. C. Word, and M. Godinez, Nano Lett., 5, 2005 (2005).

14. B. Marí, F. J. Manjón, M. Mollar, J. Cembrero, and R. Gómez, Appl. Surf. Sci., 252, 2826 (2006)

15. B. Marí, J. Cembrero, F. J. Manjon, M. Mollar, and R. Gómez, Phys. Status Solidi A, 202, 1602 (2005)

16. Q. Wang, G. Wang, J. Jie, X. Han, B. Xu, and J. G. Hou, Thin Solid Films, 492, 61 (2005).

17. B. Marí, M. Mollar, A. Mechkour, B. Hartiti, M. Perales, and J. Cembrero, Microelectron. J., 35, 79 (2004).

18. J. Wang, G. Du, Y. Zhang, B. Zhao, X. Yang, and D. Liu, J. Cryst. Growth, 263, 269 (2004).

19. F. Leiter, H. Alves, D. Pfisterer, N. G. Romano, D. M. Hofmann, and B. K. Meyer, Physica B, 201, 340 (2003).

20. T. Pauporte, F. Bedioui, and D. Lincot, J. Mater. Chem., 15, 1552 (2005). 